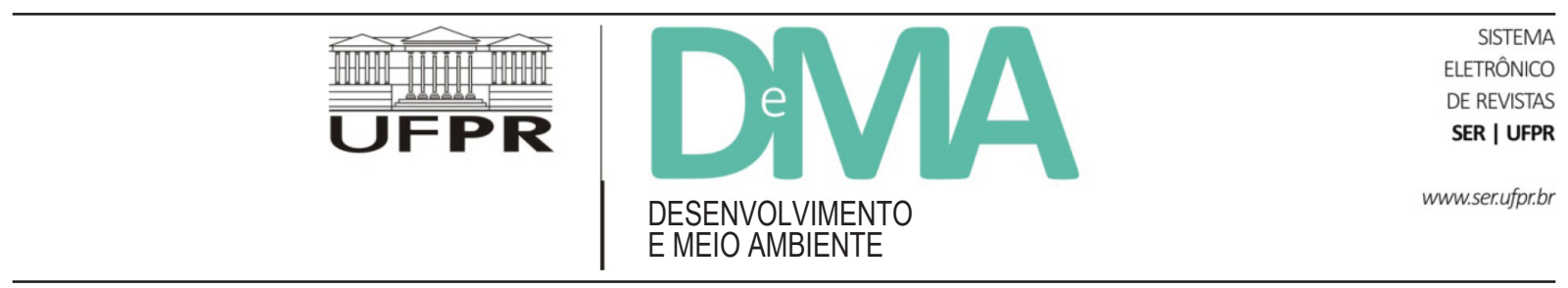

\title{
A contribuição da memória nos estudos de desenvolvimento rural: um olhar sobre as matas ciliares de Caraá, Rio Grande do Sul
}

\section{The Contribution of Memory in Studies of Rural Development: a View about the Riparian Forests of Caraá, Rio Grande do Sul}

\author{
Janine da Silva DEMENIGHI ${ }^{1 *}$, Rumi Regina KUBO ${ }^{1}$ \\ ${ }^{1}$ Programa de Pós-Graduação em Desenvolvimento Rural (PGDR), Universidade Federal do Rio Grande do Sul (UFRGS), Porto Alegre, RS, Brasil. \\ *E-mail de contato: janinedsd@yahoo.com.br
}

Artigo recebido em 6 de outubro de 2014, versão final aceita em 29 de julho de 2015.

RESUMO Este trabalho apresenta a perspectiva teórica da memória coletiva e o uso conjunto de ferramentas metodológicas distintas como proposta de compreensão das percepções de agricultores familiares sobre as áreas conhecidas como matas ciliares, de modo a subsidiar a reflexão sobre o desenvolvimento rural. Tendo como local de estudo o município de Caraá, Rio Grande do Sul, onde se encontra a nascente de um dos rios mais poluídos do Brasil - o Rio dos Sinos -, a pesquisa envolveu 25 famílias no período compreendido entre abril e junho de 2013 . A partir dos instrumentos conhecidos como linha do tempo e mapa da área, além da realização de caminhadas de reconhecimento do local, os significados e usos das matas ciliares puderam ser identificados. Durante a construção da linha do tempo - em que os relatos foram expostos de forma livre e dentro de um contexto mais amplo da trajetória das famílias - os significados atribuídos às matas ciliares se mostraram diferentes daqueles expostos após o questionamento sobre o motivo pelo qual a área era mantida, sendo que nesse último caso prevaleceram os aspectos ecológicos. O desenho da área possibilitou um processo reflexivo sobre a configuração atual do espaço, e a maioria das famílias incluiu as matas ciliares na ilustração. A análise conjunta das informações obtidas a partir das distintas ferramentas metodológicas permitiu reconhecer diferentes percepções das matas ciliares, como sua relação com uma faixa estreita de vegetação, ao mesmo tempo que era citada como "preservada" ou "não usada". Estudos de memória coletiva associando diferentes instrumentos metodológicos apresentam-se, dessa forma, como propostas desafiadoras na compreensão das percepções, constituindo-se como caminhos relevantes ao entendimento das complexidades inerentes ao meio rural.

Palavras-chave: memória coletiva; agricultores familiares; matas ciliares.

ABSTRACT This study presents the theoretical perspective of collective memory and the combined use of distinct methodological tools as a proposal to comprehend the perceptions of family farmers about the areas known as riparian forests, as a subsidy to reflect on rural development. The study site is the township of Caraá, Rio Grande do Sul, where the source of one of the most polluted rivers in Brazil - Rio dos Sinos - is located. The research 
involved 25 families in the period between April and June 2013. From the instruments known as timeline and map of the area, in addition to conducting site reconnaissance walks, the meanings and uses of riparian areas could be identified. During the construction of the timeline - where the reports were exposed freely and within the broader context of the trajectory of families - the meanings attributed to riparian forests were different from those exposed after questioning about why the area was maintained. In this last case, ecological aspects prevailed. The design of the area enabled a reflective process about the current configuration of space, and most families included riparian forests in the illustration. The joint analysis of information obtained from different methodological tools allowed to recognize different perceptions of riparian forests as their relationship with a narrow strip of vegetation, at the same time in which it was cited as "preserved" or "unused". Studies of collective memory associating different methodological tools are presented, thus, as challenging proposals in comprehension of perceptions, becoming an important way to the understanding of the complexities inherent to rural environment.

Keywords: memory; family farmers; riparian forests.

\section{Introdução}

A centralidade dos estudos direcionados ao meio rural se justifica não somente pelo fato das populações rurais se relacionarem à produção agrícola, mas também, como lembra José de Souza Martins, por serem “autoras e consumadoras de um modo de vida que é também um poderoso referencial de compreensão das irracionalidades e contradições que há fora do mundo rural" (Martins, 2000, p. 9). Esse modo de vida, por sua vez, abrange diferentes relações entre ser humano e natureza, fazendo com que a dimensão ambiental do que se entende por desenvolvimento rural - processo que envolve ainda as dimensões econômica, sociocultural e político-institucional (Kageyama, 2008) e busca a "melhoria das condições de vida da população residente no meio rural" (Kageyama, 2009, p. 267) - possa ser aprofundada. Como contribuem Van Der Ploeg et al. (2000), o paradigma da modernização da agricultura vem sendo substituído pelo do desenvolvimento rural, processo enraizado em tradições históricas, em que objetivos como as sinergias com os ecossistemas locais estão presentes.
Nesse contexto de relações entre ser humano e natureza, chama-se atenção para o uso de espaços fundamentais para a manutenção da qualidade e quantidade de um dos elementos mais importantes para a vida de modo geral - a água - como é o caso das matas ciliares, "[...] tipos de formações florestais ocorrentes às margens dos cursos d'água" (Martins, 2011, p. 28). Embora sejam responsáveis pela proteção do solo, fornecimento de alimentos, conservação da biodiversidade, melhoria do clima e dos recursos hídricos, essas matas têm sofrido pressões oriundas das dinâmicas sociais associadas à expansão urbana, industrial e do intensivo uso do solo, o que acaba por comprometer suas funções. Função ambiental, que, por sua vez, integra o que se entende como desenvolvimento rural e, segundo Kageyama $(2009$, p. 250) "passa a receber mais atenção e demanda do meio rural a criação e proteção de bens públicos e quase-públicos, como paisagem, florestas e meio ambiente em geral".

Considerando que o espaço rural ${ }^{1}$ contempla parte significativa dessas formações, destaca-se o papel dos agricultores familiares no contato com essas áreas, “[...] pela sua escala menor, pela maior capacidade ge-

\footnotetext{
1 "Esse mundo rural se move em um espaço específico, o espaço rural, entendido em sua dupla face. Em primeiro lugar, enquanto um espaço físico diferenciado. Faz-se, aqui, referência à construção social do espaço rural, resultante especialmente da ocupação do território, das formas de dominação social que tem como base material a estrutura de posse e uso da terra e outros recursos naturais, como a água, da conservação e uso social das paisagens naturais e construídas e das relações campo-cidade. Em segundo lugar, enquanto um lugar de vida, isto é, lugar onde se vive (particularidades do modo de vida e referência "identitária") e lugar de onde se vê e se vive o mundo (a cidadania do homem rural e sua inserção na sociedade nacional)" (Wanderley, 2001, p. 32).
} 
rencial, por sua flexibilidade e por sua maior aptidão à diversificação de culturas e à preservação dos recursos naturais" (Ehlers, 1996, p. 150). Dessa forma, a escuta desses agricultores e a compreensão das relações estabelecidas, que refletem nas atuais conformações dos espaços, possibilitam refletir e, quiçá, melhor intervir nas diversas realidades, processo de escuta esse que pode ser formulado a partir da perspectiva da memória coletiva, amparado na definição proposta por Henri Bergson de que "[...] a memória de um ser vivo parece medir antes de tudo a capacidade de sua ação sobre as coisas [...]" (Bergson, 1990, p. 187).

O estudo da memória pode ser estabelecido a partir de diferentes instrumentos ou estratégias metodológicas, sendo que o presente trabalho se propõe a apresentar o uso conjunto de ferramentas distintas (linha do tempo, mapa da área, caminhadas de reconhecimento do local) como proposta para a compreensão das percepções ${ }^{2}$ de agricultores familiares sobre as matas ciliares. Como aponta Woortmann (2009, p. 128) em seu estudo com sitiantes sergipanos, "Quanto mais nos inteirarmos de contextos, mais respeitaremos - e faremos respeitar por outros - sua relação com a natureza. E entenderemos as estratégias inteligentes desenvolvidas".

Como área de estudo, a pesquisa é voltada ao município de Caraá, Rio Grande do Sul, no qual se encontra a nascente do Rio dos Sinos, cuja bacia hidrográfica está entre as mais críticas do Brasil no que se refere à qualidade da água (ANA, 2013). Nesse contexto, destaca-se o papel fundamental das matas ciliares, enquanto "[...] filtros que amortecem os impactos" (Barrella et al., 2009, p. 200), contribuindo na "[...] estabilidade dos ciclos hidrológicos e biogeoquímicos das Bacias Hidrográficas" (Borges et al., 2011, p. 1205).

O trabalho de campo foi realizado em três localidades do município de Caraá, no período compreendido entre abril e junho de 2013, sendo que 25 famílias $^{3}$ integraram a pesquisa. A faixa etária dos participantes ${ }^{4}$ variou de 33 a 78 anos, o nível de escolaridade foi o Ensino Fundamental incompleto e as famílias possuíam entre dois e cinco integrantes ${ }^{5}$. No que se refere às áreas visitadas, em todos os casos foi citado o acesso à terra a partir de relações de parentesco (herança ou compra de áreas de familiares), sendo que a extensão das propriedades variou de 4 a 69 hectares $^{6}$ e alguns estabelecimentos eram compartilhados entre irmãos. No que se refere à renda das famílias que participaram da pesquisa, na localidade Fraga identificou-se o predomínio da venda de feijão e gado e o extrativismo da planta conhecida como samambaia-preta (Rumohra adiantiformis); na localidade Caraá Central destacou-se a venda de gado e aipim, além da aposentadoria; e na localidade Linha Padre Vieira predominou a produção de verduras, sendo a batata-doce e o repolho os mais comercializados.

O caminho percorrido teórica e metodologicamente é descrito a seguir, tendo como base o aporte da memória coletiva e o percurso estabelecido a partir da aproximação com o município de Caraá. A leitura desses processos buscou contribuir para ampliar os recursos teórico-metodológicos para análise do mundo rural e do desenvolvimento rural.

\footnotetext{
${ }^{2}$ No que se refere à percepção, destaca-se a contribuição de Merlau-Ponty (1996, p. 13) quando afirma que "não é preciso perguntar-se se nós percebemos verdadeiramente um mundo, é preciso dizer, ao contrário: o mundo é aquilo que nós percebemos".

${ }^{3}$ Como contribui Carneiro (2000, p. 156) “[...] a unidade familiar não se limita ao grupo de pessoas formado por laços de aliança ou de consanguinidade; ela deve ser percebida também como um valor (próximo a um sentimento de identidade) que integra seus membros, dando sentido às suas relações e informando as suas estratégias coletivas e individuais".

${ }^{4}$ Para essa análise, consideraram-se os casais, ou apenas a esposa ou marido, no caso de apenas um deles ter participado. Vale destacar, no entanto, que além desses adultos, em três entrevistas houve a participação de outros familiares adultos. Na localidade Fraga, uma das entrevistas contou com a participação da mãe do marido, de 70 anos, e, em outra visita, o filho do casal, de 35 anos e a nora de 36 anos estiveram presentes (em ambos os casos esteve-se diante de três gerações - avós, pais e filhos). Na Linha Padre Vieira, em uma visita, a mãe do marido, de 69 anos, acompanhou a pesquisa. Em alguns momentos (sete visitas), houve a presença dos filhos também.

${ }^{5}$ Considerou-se como integrante, nesse caso, as pessoas que residem em cada uma das áreas visitadas.

${ }^{6}$ Fazendo um comparativo com o módulo fiscal - que em Caraá equivale a 18 hectares -, das 25 famílias visitadas, dez apresentam área de até um módulo, onze possuem de um a dois módulos e quatro apresentam área de dois a quatro módulos.
} 


\section{Memória coletiva}

Enquanto uma leitura não apenas do passado, mas também do presente, a memória coletiva possibilita um esforço de (re)construção do percebido e vivido por diferentes grupos a partir de um recorte temporal, sendo "uma corrente de pensamento contínuo, de uma continuidade que nada tem de artificial, pois não retém do passado senão o que ainda está vivo ou é capaz de viver na consciência do grupo que a mantém" (Halbwachs, 2006, p. 192). Diferencia-se da história, segundo esse mesmo autor, pelo fato de examinar os grupos por dentro, e não de fora, partindo dos acontecimentos vivenciados por seus integrantes.

Nos estudos de memória, destacam-se os elementos "tempo" e "espaço", visto que "é no tempo, no tempo que é de um determinado grupo que ele procura encontrar ou reconstituir a lembrança, e é no tempo que se apoia" (Halbwachs, 2006, p. 146). Ao retroceder no tempo, por sua vez, é possível acompanhar e entender a configuração atual dos espaços, considerando que

Não há memória coletiva que não aconteça em um contexto espacial. Ora, o espaço é uma realidade que dura: nossas impressões se sucedem umas às outras, nada permanece em nosso espírito e não compreenderíamos que seja possível retomar o passado se ele não estivesse conservado no ambiente material que nos circunda. É ao espaço, ao nosso espaço - o espaço que ocupamos, por onde passamos muitas vezes, a que sempre temos acesso e que, de qualquer maneira, nossa imaginação ou nosso pensamento tem de se fixar para que essa ou aquela categoria de lembranças reapareça. (Halbwachs, 2006, p. 170)

Considerando o modo de vida dos agricultores familiares, o elemento espaço tende a cumprir um papel ainda mais evidente no que se refere à memória, visto a relação de proximidade diferenciada que estabelecem com a terra, "[...] que melhor responde a noção de sustentabilidade [...]" (Almeida, 1999, p. 52). Além disso, como chama atenção Bosi (1994, p. 443) "o espaço que encerrou os membros de uma família durante anos comuns, há de contar-nos algo do que foram essas pessoas.
Porque as coisas que modelamos durante anos resistiram a nós com sua alteridade e tornaram algo do que fomos". Destacam-se, nesse ponto, as áreas rurais que apresentam como característica o uso da terra perpassado por diferentes gerações, que ocupam um mesmo espaço ao longo do tempo, produzindo diferentes memórias e fazendo desse espaço seu território. Litte (2002, p. 3) contribui nesse sentido quando define territorialidade como "esforço coletivo de um grupo social para ocupar, usar, controlar e se identificar com uma parcela específica de seu ambiente biofísico, convertendo-a assim em seu 'território' [...]”.

A atenção ao coletivo foi enfatizada por Halbwachs em sua teoria relacionada à memória, em que se destacou que "Nossos sentimentos e nossos pensamentos mais pessoais têm sua origem em meios e circunstâncias sociais definidos [...]" (Halbwachs, 2006, p. 41). O papel do indivíduo não é desconsiderado, nesse caso, mas chama-se atenção para o fato de existir um contexto social mais amplo ao qual ele se encontra conectado, já que "[...] seus pensamentos e seus atos se explicam por sua natureza de ser social e porque ele não deixou sequer por um instante de estar encerrado em alguma sociedade" (Halbwachs, 2006, p. 42).

O olhar ao indivíduo inserido nesse coletivo pode apontar percepções distintas de um mesmo espaço, já que, como afirma Halbwachs (2006, p. 69),

[...] se a memória coletiva tira sua força e sua duração por ter como base um conjunto de pessoas, são os indivíduos que se lembram, enquanto integrantes do grupo. Dessa massa de lembranças comuns, umas apoiadas nas outras, não são as mesmas que aparecerão com maior intensidade a cada um deles. De bom grado, diríamos que cada memória individual é um ponto de vista sobre a memória coletiva, que este ponto de vista muda segundo o lugar que ali ocupo e que esse mesmo lugar muda segundo as relações que mantenho com outros ambientes.

Dessa forma, a perspectiva da memória coletiva possibilita atentar tanto para o coletivo quanto para o indivíduo, considerando que "há fatos que não tiveram ressonância coletiva e se imprimiram apenas em nossa subjetividade. E há fatos que, embora testemunhados por outros, só repercutiram profundamente em nós $[\ldots]$ " 
(Bosi, 1994, p. 408). Essa repercussão no indivíduo permite um paralelo com a percepção, já que, de acordo com o que afirmou Bergson (1990, p. 200) "Toda percepção ocupa uma certa espessura de duração, prolonga o passado no presente, e participa por isso da memória". Assim, o aporte da memória coletiva permite identificar as diferentes percepções dos agricultores familiares de Caraá sobre as matas ciliares presentes no meio onde vivem, uma vez que se baseia em acontecimentos vividos, em um determinado tempo e espaço, afetando a coletividade e o indivíduo.

\section{Caminho percorrido em campo}

Com 7.312 habitantes e uma área de $294 \mathrm{~km}^{2}$, o município de Caraá possui $85,53 \%$ de sua população caracterizada como rural (IBGE, 2010), onde predominam estabelecimentos da agricultura familiar - $90 \%$ do total (IBGE, 2006). Apresenta remanescentes de Mata Atlântica, abriga a nascente do Rio dos Sinos e uma Unidade de Conservação denominada Área de Proteção Ambiental Municipal de Caraá. Possui ainda duas Reservas Indígenas (Terra Indígena Barra do Ouro e Terra Indígena da Varzinha) e ocupa a 494 a posição do estado do Rio Grande do Sul com relação ao Índice de Desenvolvimento Socioeconômico (IDESE), estando entre os três municípios com o menor índice (FEE, 2010). Diante dessas características, reforça-se a contribuição de Schneider (2010, p. 529) ao discorrer que falta conhecer "de que modo, afinal, os próprios agricultores reagem e quais são os recursos e estratégias que utilizam”, considerando que são eles que estão diretamente envolvidos nesse meio.

A aproximação com a realidade de Caraá contou com informações fornecidas por algumas instituições que prestam assistência aos agricultores (EMATER ${ }^{7}$,
Sindicato dos Trabalhadores Rurais, Departamento Municipal de Meio Ambiente, Secretaria Municipal de Agricultura e Secretaria Municipal de Desenvolvimento Social) sendo relevante também o contato com duas agropecuárias localizadas no centro do município (cujo fluxo de trabalhadores rurais que chegavam e saíam pôde ser observado a partir do trabalho de campo). Ao dialogar com os representantes de tais instituições, buscava-se saber onde seria possível encontrar famílias (em) que: i) ainda dependem principalmente da renda oriunda da terra (visto que no município há algumas fábricas de calçado que têm absorvido parte dos trabalhadores antes dedicados às atividades agrícolas); ii) o trabalho envolve os membros da família; iii) a área, pequena propriedade, possui algum tipo de recurso hídrico (considerando a relação com a mata ciliar); iv) vivem há algum tempo em Caraá. O resultado desses questionamentos apontou as localidades Fraga, Linha Padre Vieira e Caraá Central como as mais citadas.

Além desse recorte, a observação de espaços de discussão, que ocorrem há oito anos no município, organizados pelo Sindicato dos Trabalhadores Rurais, EMATER e representantes do setor público e realizados nas localidades consideradas como "mais agrícolas" de Caraá, também apontou algumas famílias a serem visitadas.

Em cada uma das localidades, as escolas foram identificadas como pontos de referência, devido a sua atuação na comunidade, sendo que as perguntas citadas anteriormente também foram feitas nesses espaços. Dessa forma, partindo do diálogo com representantes das escolas, dos encontros em cada localidade e das indicações oriundas das famílias visitadas - já que, como apontou Eckert (2012, p. 101), "segui os contornos das redes que eles mesmos traçavam [...]" -, foi possível desenvolver o trabalho com 25 famílias, sendo nove no Fraga, dez no Caraá Central e seis na Linha Padre Vieira.

\footnotetext{
${ }^{7}$ Associação Riograndense de Empreendimentos de Assistência Técnica e Extensão Rural.
} 


\subsection{Linha do tempo, mapa da área e caminhadas de reconhecimento}

Em cada família, buscou-se o envolvimento de, pelo menos, o casal ${ }^{8}$ na pesquisa, considerando que "é preciso também não ignorar as relações de gênero. $\mathrm{O}$ universo camponês feminino é tão importante quanto o masculino. A mulher conduz seus próprios espaços, e sua atividade é tão fundamental para a reprodução social da família quanto a do homem [...]" (Woortmann, 2009 p. 128). Com o auxílio do instrumento metodológico conhecido como linha do tempo, que "utiliza o conhecimento dos participantes sobre as mudanças ao longo do tempo que são significativas à comunidade e a influência de um aspecto específico sendo trabalhado" (Ludemann \& Boef, 2007, p. 123), as entrevistas tiveram início, sendo registradas com gravador digital e posteriormente transcritas. Esse método consiste em colocar um papel sobre a mesa, traçando-se com caneta ou lápis, uma linha no centro. À medida que as famílias definem e relatam pontos relevantes de sua trajetória - por exemplo, a quem pertenceu a área onde vivem, desde quando estão ali, como era antes e hoje, o que foi acontecendo ao longo do tempo, como usavam as áreas da beira do rio -, o registro no papel vai sendo feito, colocando-se o ano aproximado e o acontecimento. Como destaca Rechenberg (2007, p. 81)

$\mathrm{O}$ ato de rememorar configura uma ação inteligente do homem sobre o mundo, na qual este se encontra diante do desfio de povoar sua vida de sentido, reunindo, costurando, tecendo os episódios de modo que se crie a continuidade temporal necessária para seguir vivendo.

Dessa forma, rememorar remete a um processo reflexivo, possibilitando olhar para o passado e o presente, cujas transformações ocorridas ao longo do tempo podem ser compreendidas a partir do vai e vem da memória, que "[...] não obedece a uma ordem cronológica; corresponde, antes, às maneiras de ativar uma ordem com significado dos traços mnésicos nos seus esforços de acomodar o jogo de lembrar e esquecer" (Eckert, 2012, p. 27).

Esse momento inicial de construção da linha do tempo permitiu que os participantes pudessem relatar suas trajetórias sem estar limitados a responder determinadas perguntas, como ocorre com as entrevistas estruturadas e questionários. Assim, as falas seguiam o percurso delimitado por eles, "com suas lacunas, seus silêncios, suas retomadas, suas digressões" (Pietrafesa de Godoi, 1999, p. 31). Dessa forma, os significados e usos das matas ciliares, cuja pesquisa buscou identificar, apareciam inseridos em um contexto mais amplo, relatados entre um acontecimento e outro citado pelas famílias, sendo que a linha do tempo propiciou situar as lembranças, associando-as a determinadas circunstâncias. Como contribui Halbwachs (2006, p. 124):

Quando nos lembramos de uma viagem, mesmo quando não lembramos a data exata, há um contexto de dados temporais a que esta lembrança está ligada de alguma forma: foi antes da guerra, quando eu era pequeno, jovem, homem feito, em plena maturidade, eu estava com tal amigo que era mais ou menos idoso, foi em tal estação do ano, quando eu preparava um trabalho, na época de tal acontecimento... Graças a uma série de reflexões desse tipo, muitas vezes uma lembrança toma corpo e se completa.

Após o registro das diferentes lembranças a partir da linha do tempo, foi proposto a cada família que realizasse o desenho de sua área, partindo da maneira como a observa. Em uma cartolina e com o uso de canetas hidrocores, os participantes foram instigados a representar o espaço onde vivem, considerando que esses mapas "ajudam a visualizar territórios em diferentes escalas, focalizando recursos e informações específicas" (Ludemann \& Boef, 2007, p. 188), além de demonstrar como cada área é percebida. Como aponta Halbwachs (2006, p.188) “[...] há tantas maneiras de representar o espaço quanto grupos" - e foi nesse sentido que se pensou tal instrumento metodológico. Ressalta-se que esse

\footnotetext{
${ }^{8}$ Em dezesseis entrevistas contou-se com a participação do casal, sendo que nas demais houve a participação somente da esposa (cinco entrevistas) ou do marido (quatro entrevistas).
} 
momento também foi gravado e transcrito, sendo que as descrições realizadas enquanto o desenho era construído, bem como os relatos relacionados aos usos e significados das áreas, puderam ser registrados.

Com a finalização do desenho, o próximo momento, de forma geral, consistia em uma pausa para um café ou chimarrão ${ }^{9}$, proporcionado pelas famílias, que nesse ponto da conversa apresentavam-se mais à vontade com a presença da pesquisadora. Destaca-se a contribuição de Bosi (1994, p. 39) com relação a esse aspecto ao afirmar que "a memória é um cabedal infinito do qual só registramos um fragmento. Frequentemente, as mais vivas recordações afloravam depois da entrevista, na hora do cafezinho, na escada, no jardim, ou na despedida no portão". De fato, essa pausa permitia que os membros da família compartilhassem memórias até então não relatadas, além de curiosidades sobre a pesquisa e sobre o fato "de alguém de fora do Caraá" se interessar pelo município.

Após a construção da linha do tempo e do desenho, o próximo passo consistiu em caminhar pela área para observá-la, com os participantes da pesquisa. Nesse momento, a família realizava diferentes apontamentos sobre cada canto de sua terra, além de associar o que visualizava com o que colocou ou se esqueceu de colocar no desenho feito anteriormente. Registros fotográficos também puderam ser obtidos durante o reconhecimento da área, visto que "[...] ler uma paisagem é ler o tempo" (Pietrafesa de Godoi, 1999, p. 113), ajudando a compor a caracterização do local, complementada pelas anotações no diário de campo, no qual as impressões e observações feitas eram registradas ao final de cada visita.

\section{A complementariedade das ferramentas metodológicas}

Considerando a escolha de três ferramentas metodológicas complementares (linha do tempo, mapa da área e caminhada de reconhecimento do local) e a opção pela perspectiva teórica da memória coletiva, a interpretação dos achados exigiu um esforço no sentido de incluir o que foi compartilhado em cada um dos momentos, entendendo que "não há uma memória mais legítima que a outra [...]" (Eckert, 2012, p. 105). Da mesma forma, como aponta Halbwachs (2006, p. 53) "nem sempre encontramos as lembranças que procuramos, porque temos que esperar que as circunstâncias, sobre as quais nossa vontade não tem muita influência, as despertem e as representem para nós".

As percepções apontadas durante a aplicação de um mesmo instrumento metodológico se mostraram diversas em algumas situações. Como exemplo, cita-se que, enquanto o relato fluía livremente na construção da linha do tempo, os significados atribuídos às matas ciliares envolveram aspectos econômicos, normativos, ecológicos, estéticos e associados ao fato de "simplesmente ser importante", no Fraga; econômicos, normativos, ecológicos, estéticos e culturais, além do relato da não importância desses espaços e da associação com a ideia de bem-estar, no Caraá Central; e econômicos, normativos e ecológicos, além do relato da não importância desses espaços, na Linha Padre Vieira. Porém, após as famílias serem questionadas sobre o assunto, ou seja, a partir do momento em que a pesquisadora perguntou por que a vegetação da beira do rio, arroio, vertente, foi mantida, o aspecto ecológico foi enfatizado tanto na localidade Fraga como na Linha Padre Vieira (Figura 1), sendo que as questões relacionadas às esferas econômicas, normativas e a própria associação a "não importância" desses espaços praticamente não apareceram. Reforça-se, nesse sentido, o papel da linha do tempo enquanto uma forma mais livre de expor as experiências, diferentemente de um roteiro de perguntas e respostas, estando o "[...] interesse no que foi lembrado, no que foi escolhido para perpetuar-se na história de sua vida" (Bosi, 1994, p. 37).

${ }^{9}$ Bebida típica da região Sul do Brasil (e parte da Argentina e Uruguai) preparada com erva-mate (Ilex paraguariensis). 


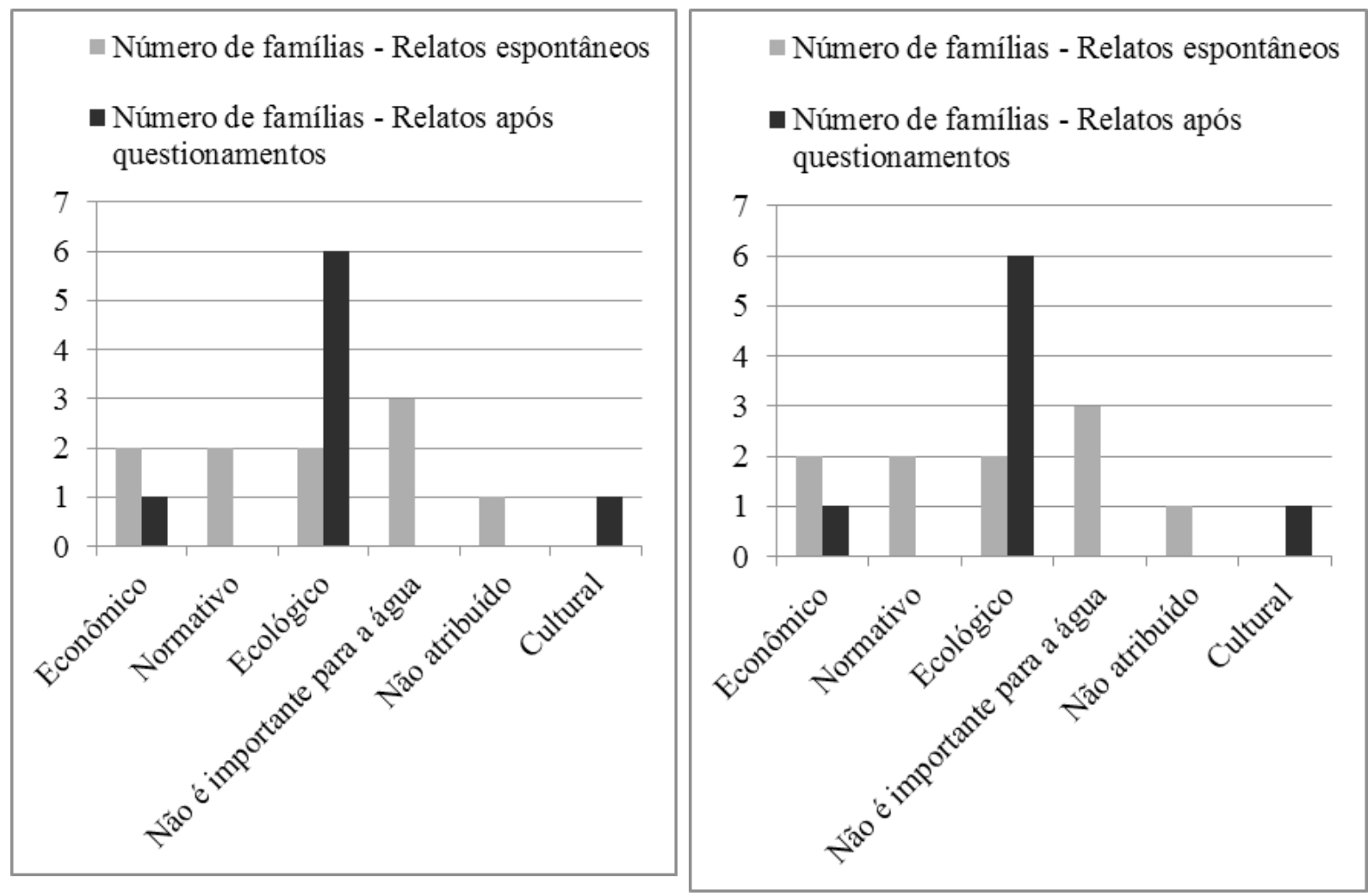

FIGURA 1 - Significados atribuídos às matas ciliares conforme o número de famílias e o momento do relato. À esquerda, dados obtidos na localidade Fraga, e à direita, dados obtidos na localidade Linha Padre Vieira.

FONTE: Elaborado pelas autoras (2013).

A observação da linha do tempo também permitiu contextualizar alguns silêncios percebidos durante a pesquisa, a exemplo de dois agricultores na localidade Fraga que não citaram o significado que atribuem às matas ciliares durante a construção da linha do tempo, bem como não aceitaram que a pesquisa fosse gravada, demonstrando certo receio. Ao acompanhar suas trajetórias, identificaram-se situações em que as famílias foram procuradas pelo órgão ambiental devido a denúncias que receberam, como relatado a seguir:
Acho que fui o primeiro a ser multado. Meu primo pediu que eu tirasse, com motosserra, o mato que tinha na beira do rio. Tirei e o IBAMA veio uns dias depois por denúncia. Vi o carro do IBAMA subindo e ouvi uns tiros. Depois o carro voltou e parou ali. Acho que falaram que era perigoso, porque além dos caras que vieram tinha um carro da polícia parado num canto da estrada, polícia em peso. Eles perguntaram onde que cortaram e eu mostrei, perguntaram quem foi e disse que fui eu, perguntaram se eu não sabia que não podia e respondi que sabia mas como meu primo mandou eu fiz. Eu já tinha ouvido falar que não podia, mas ele mandou e eu cortei ${ }^{10}$. (Comunicação oral, Família 3, Localidade Fraga).

${ }^{10}$ No decorrer do artigo, as citações oriundas das famílias visitadas são citadas dessa forma, em itálico, mantendo a fala original. Além disso, conforme combinado com os participantes, os nomes não foram citados, sendo utilizado como identificação Família 1, 2, 3 e assim sucessivamente. 
Destaca-se nesse ponto a contribuição de Pollak $(1989$, p. 6) ao afirmar que "[...] o silêncio tem razões bastante complexas", podendo, nesse exemplo, dentre outros aspectos, estar associado às marcas deixadas pela aplicação da legislação.

No que se refere aos desenhos elaborados pelos membros das famílias, observou-se que a maioria dos participantes inclui a mata ciliar na representação de sua terra, conforme representado na Figura 2. Chama- -se atenção para o fato de que o simples ato de refletir sobre a configuração do espaço, previamente ao início do traçado, já representa um processo de repensar cada "canto" da propriedade. Ao "se dar conta" de aspectos esquecidos durante o desenho, por exemplo, como colocado pelo membro da Família 3 do Caraá Central: "Agora que eu vi que esqueci de colocar a acácia no desenho", amplia-se o olhar para os detalhes antes despercebidos.

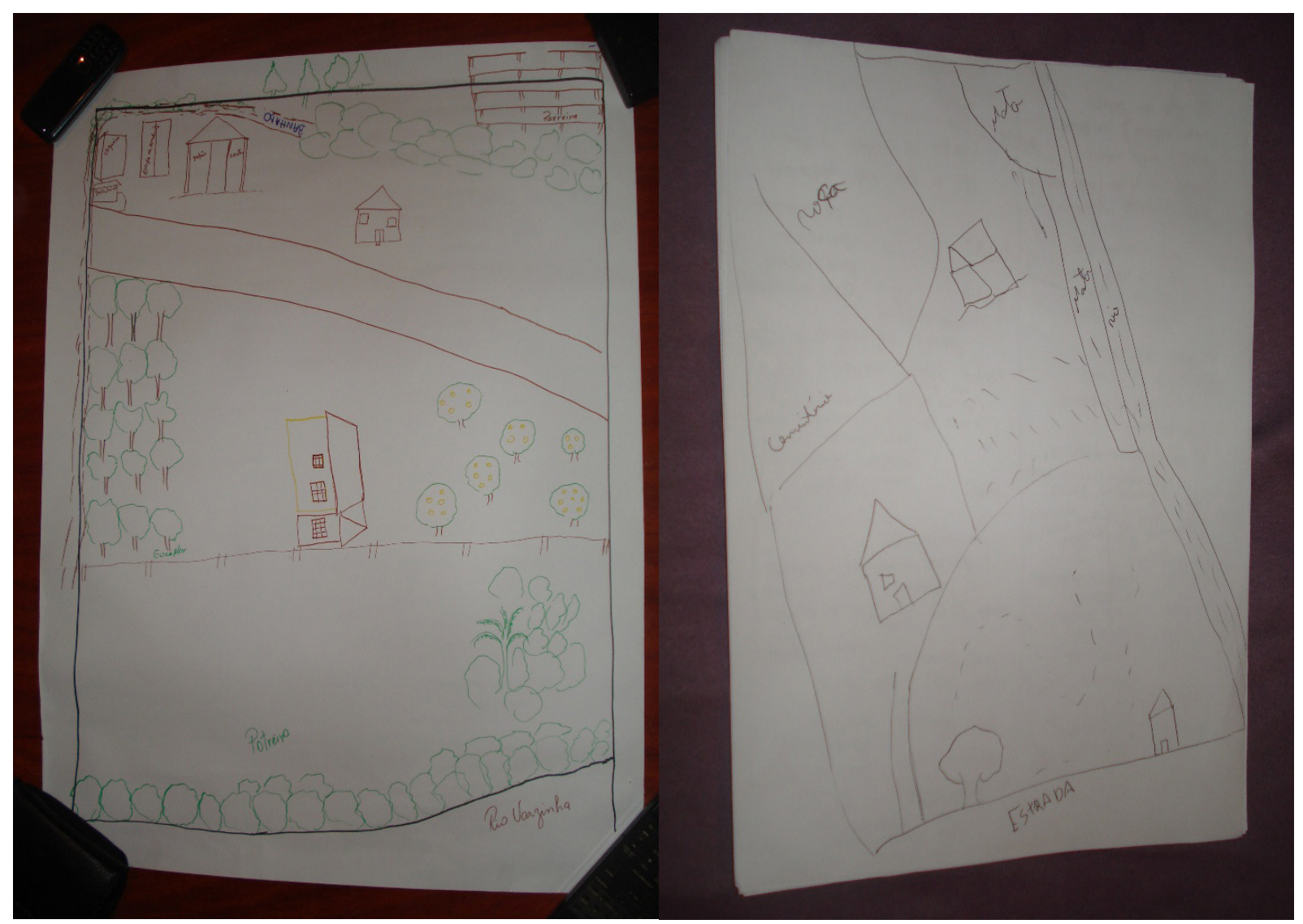

FIGURA 2 - À esquerda, desenho construído pela Família 6 da localidade Fraga, e à direita desenho construído pela Família 2 da localidade Linha Padre Vieira.

FONTE: Fotografias da autora (2013). 
As famílias, enquanto desenhavam, ainda descreviam a área com detalhamentos, relatos de largura da vegetação e impressões.

Então aqui tem uma reserva que é do rio. Tinha uma lavoura aqui e uma reservazinha aqui assim também na beirada, de um lado e de outro. Aqui é mato também, tem uma beirada de mato, é pouco, aqui é pouco mato. Alfafa até bem dizer a beira do rio, porque aqui ficou uma lasquinha, ali não plantei. Tem a beiradinha da beira do rio né. Sempre tem árvore na beira do rio, ali tem bastante, mas não é assim, dizer que tem 10 metros. (Comunicação oral, Família 5, Localidade Caraá Central).

Nesse relato é possível identificar a ideia da mata enquanto reserva, o uso da área para o plantio de alfafa, a presença da noção de "lasquinha" de vegetação e ainda o conhecimento de que existe uma exigência de determinada largura de mato em torno do rio. Como contribui Pietrafesa de Godoi (1999, p, 113), "Cada aspecto, cada detalhe dos lugares, possui um sentido inteligível somente para os membros do grupo, porque todas as partes do espaço por ele ocupadas passaram a se constituir em pontos de marcação de um tempo por ele vivido". Essas informações, relatadas no decorrer da elaboração do desenho, enfatizam a relevância desse instrumento nos estudos do meio rural, cuja complexidade de relações ali presentes requer ferramentas que atentem para os mais diversos aspectos.

Vale chamar atenção para a construção do mapa pela Família 9 do Caraá Central, a qual, além de representar o arroio e a mata ciliar da nascente até o ponto em que desagua no arroio de maior vazão, foi "se dando conta" de que deveria refazer o desenho enquanto rabiscava: "Comecei errado, tinha que ter começado lá e deixar espaço aqui pro rio", "Podia vir outro dia pra gente arrumar, andar pela terra". Faz-se, nesse exemplo, a partir do desafio de representar adequadamente um pedaço da paisagem, um exercício de releitura do espaço, processo fundamental no que se refere à continuidade das atividades considerando as capacidades e limitações dos ambientes. Acionam-se, nessa operação, aspectos práticos da experiência individual, assim como elementos estéticos.
Além do cuidado em identificar as experiências relatadas em cada um dos momentos com as famílias, o olhar sobre o conjunto metodológico aplicado permitiu importantes reflexões. Como exemplo, cita-se a consideração da mata ciliar como "preservada" ou "não usada" no relato da linha do tempo, enquanto que, em algumas situações, na caminhada de reconhecimento da área identificava-se ausência de vegetação, presença de infraestruturas ou uma faixa estreita em torno do curso d'água, por vezes não chegando a um metro de largura. Exemplo disso foi observado no relato da Família 7 do Fraga, que apontou: "Hoje no arroio 90\% têm mato na volta". No entanto, ao percorrer a área, observou-se um pequeno número de árvores em torno do arroio, o que instiga o questionamento sobre o que se entende como mato e de que forma as informações associadas a esse tema estão sendo apreendidas. Reforça-se, nesse caso, a necessidade de utilizar ferramentas variadas para captar essas diversidades, já que "[...] a fala é sempre situacional e não pode ser dissociada do contexto em que ocorre, mas, nem por isso, discursos e práticas são realidades necessariamente opostas - uma operando por distorção à outra - mas, antes pistas diferentes e complementares [...]" (Pietrafesa de Godoi, 1999, p. 36).

\section{Considerações finais}

A partir do que foi exposto e retomando a proposta inicial desse trabalho - apresentar o uso conjunto de ferramentas distintas na compreensão das percepções de agricultores familiares sobre as matas ciliares de Caraá, sob o aporte teórico da memória coletiva -, é possível inferir a relevância de tais instrumentos como forma de olhar o passado e o presente, além de permitir refletir sobre os caminhos futuros. O percurso teórico-metodológico aqui descrito se apresenta como uma proposta para contribuir aos estudos sobre percepção, considerando que possibilita identificar, a partir de ferramentas distintas daquelas centradas majoritariamente em perguntas e repostas, os significados atribuídos a espaços fundamentais à vida em sua totalidade, bem como os usos que estão sendo feitos de áreas como as matas ciliares. A organização das ideias possibilitada pela linha do tempo 
facilitou a retomada de lembranças associadas ao espaço do qual os agricultores familiares estão próximos, assim como o exercício de desenhar refletiu em um processo particular de reflexão das práticas. Quando associados ao reconhecimento do local por meio de caminhadas pela área, tais instrumentos se configuram como importantes ferramentas de pesquisa a serem consideradas na compreensão do mundo rural.

Nesse sentido, destaca-se a contribuição de Van Der Ploeg et al. (2000, p. 400) quando afirma que "o desenvolvimento rural não se trata apenas de "coisas novas' que estão sendo adicionadas a situações estabelecidas. Trata-se de realidades enraizadas historicamente e emergentes que estão atualmente reaparecendo [...]”. O estudo da memória permite (re)construir, (re)pensar, (re) valorizar tais realidades, pois, como contribui Pietrafesa De Godoi (1999, p. 146), "poderíamos ousar dizer que a função social da memória - lembrar e advertir - é unir o começo ao fim, ligando o que foi e o porvir". Em se tratando de relações entre ser humano e natureza, cuja interdependência, por vezes desconsiderada, resulta em perda de elementos fundamentais à vida - como as matas ciliares -, utilizar-se do estudo da memória possibilita importantes reflexões sobre as diferentes formas de uso da terra, sejam elas "antigas", "novas" ou a união de

\section{Referências}

Almeida, J. Da ideologia do progresso à ideia de desenvolvimento rural sustentável. In: Almeida, J.; Navarro, Z. Reconstruindo a agricultura: ideias e ideais na perspectiva do desenvolvimento rural sustentável. Porto Alegre: Editora da UFRGS, p. 33-55, 1999.

ANA - Agência Nacional das Águas. Conjuntura dos recursos hídricos no Brasil, 2013. Disponível em: <http:// arquivos.ana.gov.br/institucional/spr/conjuntura/ANA_ Conjuntura_Recursos_Hidricos_Brasil/ANA_Conjuntura_Recursos_Hidricos_Brasil_2013_Final.pdf $>$. Acesso em: 10 mar. 2013.

Barrella, W.; Petrere Júnior, M; Smith, W. S.; Montag, L. F. A. As relações entre as matas ciliares, os rios e os peixes. In: Rodrigues, R. R.; Leitão Filho, H. F. (Eds.). Matas ciliares: conservação e recuperação. São Paulo: Editora da Universidade de São Paulo; Fapesp, p. 187-207, 2009. aspectos presentes em ambas, já que, como destacam Van Der Ploeg et al. (2000, p. 400) ao se referirem ao desenvolvimento rural, "um elemento particularmente decisivo será a combinação do 'velho' com o 'novo"”.

Fica, portanto, como desafio aos estudos sobre desenvolvimento rural no Brasil, ir além da análise e interpretação das transformações que ocorrem nas formas de produção, nas tecnologias, nas instituições e na crescente interação com os mercados. Este esforço é importante, mas será parcial e incompleto se os estudos e pesquisas não forem capazes de mostrar em que medida estas dimensões afetam as relações com o espaço e o meio ambiente, se contribuem ou não para melhoria das condições de vida da população rural fazendo, enfim, com que o desenvolvimento seja, efetivamente, um processo de mudança social. (Schneider, 2010, p. 529).

A perspectiva da memória permite, nesse sentido, apontar como ocorrem tais relações com o espaço, reconhecendo certa espessura temporal e de significados relacionados às percepções referentes às matas ciliares, com isso enfatizando a complexidade e a multiplicidade de significados e olhares que permeiam os estudos sobre o mundo rural.

Borges, L. A. C.; Rezende, J. L. P.; Pereira, J. A. A.; Coelho Júnior, L. M.; Barros, D. A. Áreas de preservação permanente na legislação ambiental brasileira. Ciência Rural, 41(7), 1202-1210, 2011. Disponível em: http://www.scielo.br/pdf/ cr/v41n7/a5611cr4051.pdf

Bosi, E. Memória e sociedade: lembranças de velhos. São Paulo: Companhia das Letras, 3. ed., 1994.

Bergson, H. Matéria e memória: ensaio sobre a relação do corpo com o espírito. São Paulo, SP: Martins Fontes, 1990.

Carneiro, M. J. Em que consiste o familiar da agricultura familiar? In: ORNAS - Ocupações Rurais Não-Agrícolas. Anais da Oficina de Atualização Temática. Londrina, Iapar, 2000, p. 153-164.

Eckert, C. Memória e trabalho: etnologia da duração de uma comunidade de mineiros do carvão (La Grand-Combe, França). Curitiba: Appris, 2012. 
Ehlers, E. Agricultura sustentável: origens e perspectivas de um novo paradigma. São Paulo: Livros da Terra, 1996.

FEE-FundaçãodeEconomiaeEstatística.Índice de Desenvolvimento Socioeconômico (IDESE 2010). Disponível em: <http://www.fee.rs. gov.br/indicadores/indice-de-desenvolvimento-socioeconomico/ serie $=$-historica-nova-metodologia/?ano2010=\&letra=C\&ordemmunicipios>. Acesso em: 10 jun. 2014.

Halbwachs, M. A memória coletiva. São Paulo: Centauro, 2006.

IBGE - Instituto Brasileiro de Geografia e Estatística. Censo agropecuário 2006. Disponível em: <http:/www.ibge.gov.br/ home/estatistica/economia/agropecuaria/censoagro/agri_familiar_2006/default.shtm>. Acesso em: 15 set. 2012.

IBGE - Instituto Brasileiro de Geografia e Estatística. Primeiros dados do censo 2010. Disponível em: < http://www.censo2010. ibge.gov.br/primeiros_dados_divulgados/index.php?uf=43>. Acesso em: 15 set. 2012.

Kageyama, A. Desenvolvimento rural: conceitos e aplicações ao caso brasileiro. Porto Alegre: Editora da UFRGS, 2008.

Kageyama, A. Desenvolvimento rural no Rio Grande do Sul. In: Schneider, S. (Org.). A diversidade da agricultura familiar. Porto Alegre: Editora da UFRGS, p. 245-272, 2009.

Little, P. Territórios sociais e povos tradicionais no Brasil: por uma antropologia da territorialidade. Série Antropologia, 322, 1-32, 2002. Disponível em: http://www.direito.mppr.mp.br/ arquivos/File/PaulLittle.pdf

Ludemann, R.; Boef, W. S. Processos e ferramentas de diagnóstico participativo. In: Boef, W. S.; Thijssen, M. H.; Ogliari, J. B.; Sthapit, B. R. (Org.). Biodiversidade e agricultores: fortalecendo o manejo comunitário. Porto Alegre, RS: L\&PM, p. 118-127, 2007.

Martins, J. S. O futuro da sociologia rural e sua contribuição para a qualidade de vida rural. Estudos Sociedade e Agricultura, 15(43), 5-12, 2000. Disponível em: http://r1.ufrrj.br/esa/V2/ ojs/index.php/esa/article/view/174/170
Martins, S. V. Recuperação de matas ciliares. Viçosa, MG: CPT, 2. ed., 2011.

Merlau-Ponty, M. Fenomenologia da percepção. São Paulo: Martins Fontes. 1996.

Pietrafesa de Godoi, E. O trabalho da memória: cotidiano e história no sertão do Piauí. Campinas, SP: Editora da Unicamp, 1999.

Pollak, M. Memória, esquecimento, silêncio. Estudos Históricos, 2(3), 3-15, 1989. Disponível em: http://bibliotecadigital. fgv.br/ojs/index.php/reh/article/view/2278/1417

Rechenberg, F. Vamo falá do nosso Lami: estudo antropológico sobre memória coletiva, cotidiano e meio ambiente no Bairro Lami, Porto Alegre. Porto Alegre, Dissertação (Mestrado em Antropologia Social) - UFRGS, 2007. Disponível em: http://www.lume.ufrgs.br/bitstream/handle/10183/11256/000606125.pdf?sequence $=1$

Schneider, S. Situando o desenvolvimento rural no Brasil: o contexto e as questões em debate. Revista de Economia Politica, 30(3), 511-531, 2010. Disponível em: http://www.ufrgs. br/pgdr/arquivos/773.pdf

Van Der Ploeg, J. D.; Renting, H.; Brunori, G.; Knickel, K.; Mannion, J.; Marsden, T.; Roest, K.; Sevilla-Guzmán, E.; Ventura, F. Rural development: from practices and policies towards theory. Sociologia Ruralis, 40(4), 391-408, 2000.

Wanderley, M. N. B. A ruralidade no Brasil moderno: por um pacto social pelo desenvolvimento rural. In: Giarraca, N. (Comp.) ¿Una nueva ruralidade en América Latina? Buenos Aires: CLACSO/ASDI, p. 31-44, 2001. Disponível em: http://bibliotecavirtual.clacso.org.ar/ar/libros/rural/ wanderley.pdf

Woortmann, E. F. O saber camponês: práticas ecológicas tradicionais e inovações. In: Godoi, E. P.; Menezes, M. A.; Marin, R. A. (Orgs.). Diversidade do campesinato: expressões e categorias. São Paulo: Editora UNESP/Brasília, v. 2, p. 119-129, 2009. 